\title{
Nursery inoculation with the arbuscular mycorrhizal fungus Glomus viscosum and its effect on the growth and physiology of hybrid artichoke seedlings
}

\author{
Angela Campanelli, Claudia Ruta, Anna Tagarelli, Irene Morone-Fortunato \\ Dipartimento di Scienze delle Produzioni Vegetali, Università di Bari, Italy
}

\begin{abstract}
Most nurseries operating in Italy adopt high technologies and produce transplants that well suit and satisfy the grower's need to produce high value crops. Mycorrhizas are discussed as a tool for improving and developing plant production in the nursery. Much research has been carried out on mycorrhizal symbiosis and we now know more about the symbiontic relationship between fungi and host plants. Plants receive numerous benefits from this symbiosis which are more macroscopic the earlier in the ontogenetic cycle this symbiosis is established. Therefore, it appears that the most effective period in which the inoculum should be made corresponds to the in-nursery growing stage. The earlier the plant is inoculated, the more evident the effect will be. In this study, several aspects related to the physiological foundations of arbuscular mycorrhiza in artichoke plants are presented. The main goal was to study the effects of mycorrhiza on the growth and physiological parameters of three hybrids of artichokes growing in the nursery. The experimental $3 \times 2$ design included two treatments (with or without arbuscular mycorrhizal fungi) and three hybrids of artichokes marketed by Nunhems (Opal F1, Madrigal F1, Concerto F1). Mycorrhizal plants have greater shoot length, leaf area, shoot and root fresh and dry mass, and root density. This also corresponded with increased photosynthetic rates and stomatal conductance of mycorrhizal plants. Mycorrhizal colonization improves relative water content
\end{abstract}

Correspondence: Angela Campanelli, Dipartimento di Scienze Agro-ambientali e Territoriali, Università di Bari, via Orabona 4, 70126 Bari, Italy. Tel. +39.080 .5443045 Fax: +39.080 .5442976$

E-mail: lillyc80@libero.it

Key words: Cynara cardunculus L. var. scolymus Fiori, arbuscular mycorrhiza, nursery.

Acknowledgements: the authors are grateful to the Italian Ministry of Agricultural, Food and Forestry Policies for providing financial support (Project CAR VARVI). Thanks to Dr Nicola Calabrese for his precious advice and for providing achenes of hybrids of Madrigal F1, Opal F1, Concerto F1.

Received for publication: 8 October 2011.

Accepted for publication: 2 July 2011.

(C) Copyright A. Campanelli et al., 2011

Licensee PAGEPress, Italy

Italian Journal of Agronomy 2011; 6:e25

doi:10.4081/ija.2011.e25

This work is licensed under a Creative Commons Attribution NonCommercial 3.0 License (CC BY-NC 3.0). and increases proline concentration in vegetal tissue. Inoculation produced the most beneficial effect on hybrid Madrigal F1 and on hybrid Opal F1; the best mycorrhizal affinity was enhanced when compared to hybrid Concerto F1. The results showed that mycorrhizal symbiosis stimulated the growth of inoculated seedlings providing a qualitatively good propagation material.

\section{Introduction}

Nowadays, growers prefer to purchase seedlings from nurseries in order to ensure the uniformity and quality of the propagation material. There is no doubt that even in Italy the developments in horticulture observed over the last decades are related to the expansion of nursery production that has allowed producers to be provided with seedlings which are ever closer to perfection in their capability of ensuring good production results. The superior quality requirements for in-nursery produced plants are met by using high-input cultivation techniques, such as the use of highly selected substrates and the choice of slow release fertilizers (Gianquinto and Magnifico, 2003).

In-nursery plant production is aimed at producing well-shaped plants with good root systems; in this respect, the nursery sector could greatly benefit from the application of mycorrhizal fungi for quality plant production (Barea et al., 2000; Jeffries et al., 2003). Moreover, mycorrhizal inoculation represents the most environmentally safe system for managing pests in plant propagation (Hartman et al., 2002). The direct influence of mycorrhizal inoculation on root morphology, physiology and architecture (Lynch, 1995; Cruz et al., 2004; Green et $a l ., 2005)$ is a key factor in understanding the improvement in vegetable productiveness resulting from the better water supply. The symbiotic relationship between plants and mycorrhizal fungi has an influence on plant growth through other mechanisms which are not completely understood, such as the improvement of mineral nutrition and the strengthened resistance to biotic and abiotic stress.

The effectiveness of the mycorrhizal inoculation has been assessed for many other vegetable species such as leek (Hamel et al., 1997), pea (Bethlenfalvay et al., 1997), strawberry (Taylor and Harrier, 2001), lettuce and onion (Cantrell and Lindermann, 2001), asparagus (Matsubara et al., 1996), mint (Gupta et al., 2002), melon (Ruta et al., 2003), pepper (Estrada-Luna and Davies, 2003; Sensoy et al., 2007), fennel (Kapoor et al., 2004), broad bean (Rabie and Almandini, 2005), basil (Copetta et al., 2007), tomato (Al-Karaki, 2006; Hajiboland et al., 2010), zucchini plants (Colla et al., 2008), watermelon (Westphal et al., 2008) and bean (Pelaez et al., 2010).

Early inoculation of horticultural plants in the nursery is of interest with a view to field transplants: this biotechnology not only helps the plants to become established, thus improving out-planting performance (plant survival and biomass development), but it is also more 
effective in adjusting the edaphic and microbiological characteristics of the soil after transplanting (Azcón-Aguilar and Barea, 1997; Westphal et al., 2008). Indeed, transplantation with preventively inoculated plants is effective if the soil is low in such symbiontic fungi or in the event that native fungus populations are not sufficiently effective in colonizing plant roots. Since plants need to be inoculated only once during their cultivation cycle, the use of this sustainable environmentlyfriendly procedure is desirable for the quality of plant production. The affinity between plant and host is expressed by a symbiontic performance resulting from the combined action of two essential characteristics: infectivity and efficiency. Infectivity is described as the capability of the fungus to promptly and extensively colonize the root system; efficiency is measured in terms of growth response. The roots of artichoke plants, like other species, create symbiotic associations with arbuscular mycorrhizal fungi. Morone Fortunato et al. (2005) considered mycorrhizal inoculation to be a potential biofertilization strategy to increase productivity of artichoke microplants. The results obtained by Ceccarelli et al. (2010) also confirmed mycorrhizal symbiosis to be a useful tool to improve artichoke production and to obtain more resistant plants, with a high quality profile and nutraceutical content.

Over recent years, the diffusion of gamic propagation artichoke cultivars has drawn the attention of agricultural research which has introduced this culture into crop rotations, thus limiting problems of soil exhaustion. However, the aspects concerning the cultivation of these cultivars in the presence of mycorrhizal inoculum are not so present in the literature. After assessing the great availability of hybrid cultivars, it is very important to take into account the varietal behavior to mycorrhizal symbiosis. The assessment of the affinity between symbiontic fungus (species and/or strain) and plant (species, cultivar) is a prerequisite for improving the intrinsic quality of the seedlings produced.

The study aimed at assessing the effects of mycorrhizal inoculum with Glomus viscosum - strain A6 on the growth and physiology of the plant, evaluating the biometric and physiological aspects that are either typical of the cultivar or induced by symbiosis. Three different hybrid cultivars (Concerto F1, Madrigal F1, Opal F1) were examined.

\section{Materials and Methods}

\section{Plant culture and mycorrhizal inoculation}

The experiment was conducted between February and April 2010 in a greenhouse at the University of Bari, Apulia, Italy $\left(41^{\circ} 7^{\prime} 31^{\prime \prime} \mathrm{N}, 16^{\circ}\right.$ $\left.52^{\prime} 0^{\prime \prime} \mathrm{E}\right)$. The experiment took place with temperature values ranging from $10^{\circ} \mathrm{C}$ to $20^{\circ} \mathrm{C}$, relative humidity ranging from 30 to $40 \%$, under natural light conditions. Achenes from three hybrids of Cynara cardunculus L. var. scolymus Fiori marketed by Nunhems (Opal F1, Madrigal F1, Concerto F1) were surface sterilized by immersion into $0.5 \%$ mercuric chloride (0.5 mg Mercury (II) Chloride - Panreac Quimica SA / $100 \mathrm{~mL}$ sterile distilled water) for $20 \mathrm{~min}$, rinsed in sterile distilled water and germinated on wet filter paper in Petri dishes after $6 \mathrm{~h}$ of soaking in sterile distilled water under sterile conditions. After three weeks, 50 homogeneous seedlings for each hybrid were transplanted in pots (volume $=0.2 \mathrm{dm}^{3}$ ) containing commercial peat mixture. After 30 days, the plantlets of three hybrids of artichoke were transplanted into pots with a greater capacity (volume $=3 \mathrm{dm}^{3}$ ). The peat mixture (organic carbon $46 \%$, organic nitrogen $1-2 \%$, organic matter $80 \%$ ) was mixed with perlite at a $2: 1(\mathrm{v} / \mathrm{v})$ ratio, then sterilized in an autoclave $\left(121^{\circ} \mathrm{C}\right.$, 2 cycles $\mathrm{x} 25 \mathrm{~min}$ ) and used to fill the pots.

The mycorrhizal inoculum consisted of spores, mycelium and root segments of Glomus viscosum strains A6 obtained from strawberry (mycorrhizal infection $=70 \%$ ) roots after four months. For each artichoke hybrid, one half of the total of pots were inoculated with AM fungi. For the mycorrhizal treatment, each pot was inoculated with 10 $\mathrm{g}$ of inoculum containing $60-70$ fungal spores. The inoculum was placed in each pot at the base of the roots of artichoke seedlings. The plants were watered daily with distilled water.

\section{Determination of growth}

Biometric measurements were taken 90 days after mycorrhizal inoculation; this is the amount of time required to evaluate the effectiveness of the plant-fungus symbiotic relationship, expressed in terms of growth benefits. The specificity of mycorrhizal fungus-hybrid cultivar relationship is an important nursery strategy to improve vegetative status. Symbiosis effects cannot be assessed over the short time period (50 days) in which artichoke seedlings generally stay in the nursery.

Ten plants were chosen at random and harvested. The following parameters were studied: plant height $(\mathrm{cm})$ (mean height of leaves per plant), mean number of leaves per plant (n), fresh and dry leaf weight $(\mathrm{g})$, leaf area $\left(\mathrm{cm}^{2}\right)$, root density $\left(\mathrm{cm} / \mathrm{cm}^{3}\right)$, fresh and dry root weight (g). The dry weights were measured after drying samples in a pre-heated oven at $80^{\circ} \mathrm{C}$ for $48 \mathrm{~h}$ (the time required to obtain a constant weight). To measure the root density, the modified line intersect method (Tennant, 1975) was used. Total foliar area was measured on selected plants using a Licor LAI Area Meter 3100.

\section{Assessment of mycorrhizal colonization and dependency}

The roots were cleared and stained by using the Philips and Haymann method (1970) and the percentage of mycorrhizal colonization was estimated by means of the Trouvelot and Gianinazzi method (1986). For each hybrid, the mycorrhizal dependency (MD) (\%) of the plants was calculated according to Gerdermann (1975) as follows:

mycorrhizal dependency $(\%)=$ (total dry weight of mycorrhizal plant - total dry weight of non-mycorrhizal plant)*100/ total dry weight of mycorrhizal plant.

\section{Physiological parameters}

Mycorrhizal symbiosis influenced plant physiology. Some physiological parameters (stomatal conductance, SPAD measurements, chlorophyll content, leaf relative water content, proline content) were evaluated to investigate the relationship between AM fungus and plant physiology. Stomatal conductance was measured using a Leaf porometer (Model SC-1, Decagon Device, Washington, DC, USA) starting from 30 days after mycorrhizal inoculation. These measurements were made between the hours of 10:00 to 12:00 every four days, and were carried out on the completely expanded but not senescent leaves, with two repeated readings for five sample plants (both mycorrhizal and nonmycorrhizal).

The chlorophyll content was measured from 30 days after mycorrhizal inoculation, using a Chlorophyll meter SPAD502 (Minolta Camera Co. Ltd., Osaka, Japan). SPAD values were monitored every four days and were performed between the hours of 8:00 and 10:00 on the fully expanded first leaf with three readings repeated for five sample plants (both mycorrhizal and non-mycorrhizal). Stomatal conductance and SPAD values were monitored starting from 30 days after mycorrhizal inoculation, to allow symbiosis to be established and thus to evaluate the possible differences between mycorrhizal and non-mycorrhizal treatments.Chlorophyll determination was estimated at harvest on three sample plants for each hybrid and for each treatment. Prior to extraction, fresh leaf samples were cleaned with deionized water to remove any surface contamination. Chlorophyll extraction was carried out on fresh fully expanded leaf material; $1 \mathrm{~g}$ of leaf sample was ground in $90 \%$ acetone using a pestle and mortar. Absorbance was measured with a UV/visible spectrophotometer (Lambda 3B - Perkin Elmer) and chlorophyll concentrations were calculated using the equation proposed by Strain and Svec (1966):

$$
\text { Chl a }\left(\mathrm{mg} \mathrm{mL}^{-1}\right)=11.64 \times(\mathrm{A} 663)-2.16 \times(\mathrm{A} 645)
$$




$$
\text { Chl b }\left(\mathrm{mg} \mathrm{mL}^{-1}\right)=20.97 \times(\mathrm{A} 645)-3.94 \times(\mathrm{A} 663)
$$

A663 and A645 represent absorbance values read at 663 and $645 \mathrm{~nm}$ wavelengths, respectively.

Leaf relative water content (LRWC) was calculated according to the methods of Yamasaki and Dillenburg (1999). From two leaves from two randomly chosen plants per treatment, 20 homogeneous portions $(\emptyset$ $1 \mathrm{~cm})$ were obtained. These portions were weighed to obtain fresh mass (FM). In order to determine the turgid mass (TM), the leaves were floated on distilled water inside a closed Petri dish. Maximum turgidity was determined by weighing the leaves (after gently wiping the water from the leaf surface with tissue paper) until no further weight increase occurred. At the end of the imbibition period, the leaf samples were placed in a pre-heated oven at $80^{\circ} \mathrm{C}$ for $48 \mathrm{~h}$ in order to obtain dry mass (DM). All mass measurements were made using an analytical scale, with an accuracy of $0.0001 \mathrm{~g}$. Values of DM, TM and FM were used to calculate LRWC using the following equation:

$$
\text { LRWC }(\%)=(\text { FM-DM }) * 100 /(\text { TM-DM })
$$

Proline content in fresh vegetal tissue was determined according to the method described by Bates et al. (1973). Proline content was estimated on three plants for each hybrid and for each treatment. Approximately $1 \mathrm{~g}$ of artichoke tissue was weighed and homogenized in $2 \mathrm{~mL}$ of $3 \%$ sulfosalicylic acid solution. The homogenate was centrifuged at $13,000 \mathrm{~g}$ for $10 \mathrm{~min}$ and $1 \mathrm{~mL}$ of supernatant was placed in a reaction test tube. Glacial acetic acid $(1 \mathrm{~mL})$ and $1 \mathrm{~mL}$ of acid ninhydrin were added to each tube which was then closed and heated in a $100^{\circ} \mathrm{C}$ water bath for $1 \mathrm{~h}$. After the sample had cooled in an ice bath for $15 \mathrm{~min}, 2 \mathrm{~mL}$ of toluene were added to every sample and mixed on a vortex mixture for $20 \mathrm{sec}$ in a fume hood. The test tubes were left to stand at least $10 \mathrm{~min}$ to allow the separation of the toluene and aqueous phase. The toluene phase was carefully pipetted out into a glass test and absorbance was measured at $520 \mathrm{~nm}$ with a UV/visible spectrophotometer Varian Cary 50 Conc.

\section{Glasshouse salinity tolerance assessment: experimen- tal design}

The experiment had two elements: hybrid artichoke cultivars and mycorrhizal treatments, and included a conventional $3 \times 2$ factorial arrangement. Since the data were expressed as percentage (relative water content), to overcome the problem of irregularities, we transformed the measured values according to the angular transformation. ANOVA analysis and multiple comparisons of means were performed using Fisher's Least Significant Differences (LSD test).

A protectiveness level of $\mathrm{P} \leq 0.05$ was used for morphological and physiological determinations in the greenhouse; a protectiveness level of $\mathrm{P} \leq 0.01$ was used for analytical determinations in the laboratory.

\section{Results}

In agreement with the results obtained by Morone et al. (2005), for each hybrid of artichoke the beneficial effects of mycorrhizal inoculation on the morphological parameters were evident (Table 1). The inoculated plantlets were grown faster than the control, with a more robust appearance and greater root development. Root density was higher in inoculated plantlets. In addition, there was an increase in both fresh and dry weight measurements. Mycorrhizal plantlets had more leaves and higher leaf areas, respectively, than non-mycorrhizal plantlets (Table 1). Hybrids Opal F1 and Madrigal F1 obtained the best performance after mycorrhizal treatment. At the end of the trial, extensive mycorrhizal structures were observed in root systems of inoculated plants, while none were observed in non-inoculated plantlets. The root colonization percentage was higher in Hybrid Madrigal F1 (82.5\%) than it was in 0pal F1 (69.3\%) and Concerto F1 (57.9\%). These results were confirmed by the mycorrhizal dependence data. The hybrid Madrigal F1 had a higher percentage of mycorrhizal dependence (40\%) than Opal F1 (21\%) and Concerto F1 (14\%). This result implies higher affinity between Madrigal F1 and Glomus viscosum strain A6. During the experiment, mycorrhizal plants always showed a trend of higher stomatal conductance than non-mycorrhizal plantlets (Table 2). Higher stomatal conductance can be associated with the higher $\mathrm{CO}_{2}$ influx into the mesophyll tissues. SPAD values (Table 3 ) were also greater for mycorrhizal than those for non-mycorrhizal plants. The mycorrhizal treatment, indeed, significantly enhanced the foliar chlorophyll content. SPAD values showed the beneficial effects of mycorrhizal symbiosis, already evident within a month of mycorrhizal inoculation. Higher chlorophyll content was confirmed by the analysis of chlorophyll content determination in vegetal tissues, especially in hybrid Madrigal F1 and Opal F1, 90 days after mycorrhizal inoculation (Figure 1). A look at the data pre-

Table 1. Morphological characteristics of three hybrid cultivars of artichokes (Madrigal F1, Opal F1, Concerto F1) inoculated with Glomus viscosum strain $\mathrm{A6}(\mathrm{AM}+)$ compared to uninoculated plants (AM-) 90 days after mycorrhizal inoculation.

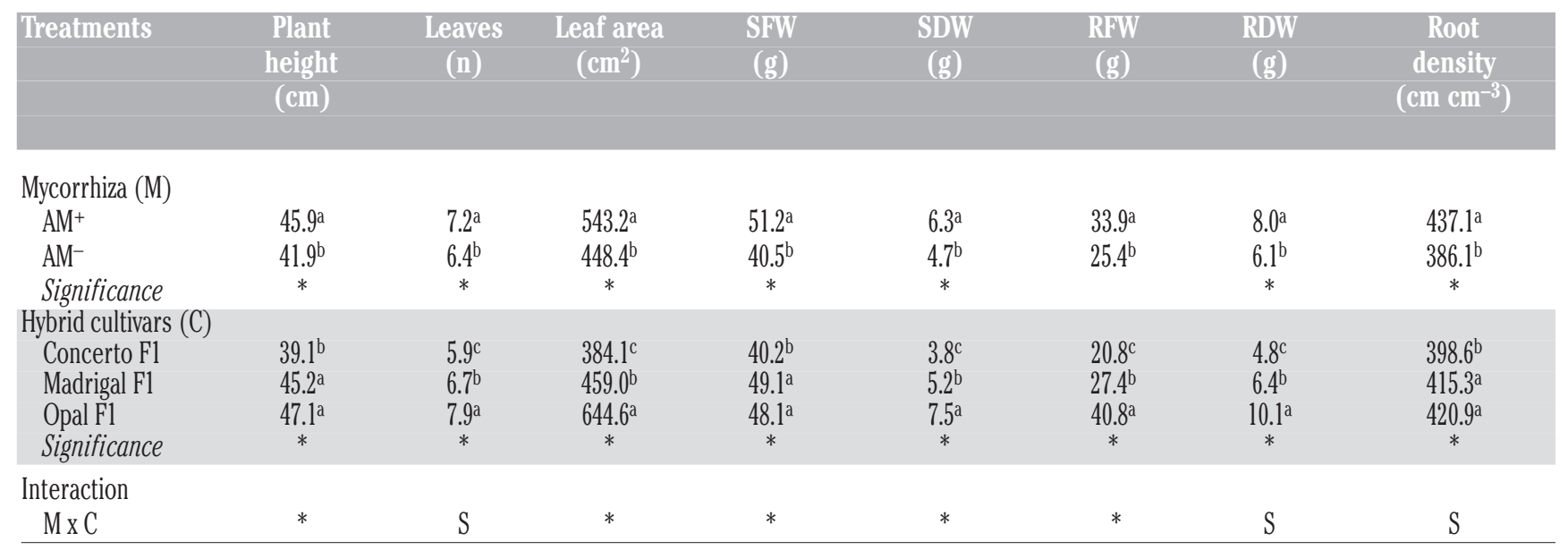

SFW, shoot fresh weight; SDW, shoot dry weight; RFW, root fresh weight; RDW, root dry weight; means in each column followed by different letters are significantly different (P $\leq 0.05$ ) according to Fisher's Least Significant Differences test; $\mathrm{S}$, significant; *non significant per $\mathrm{P} \leq 0.05$. 
Table 2. Stomatal conductance of three hybrid cultivars of artichokes (Madrigal F1, Opal F1, Concerto F1) inoculated with Glomus viscosum strain $\mathrm{A6}\left(\mathrm{AM}^{+}\right)$compared to uninoculated plants $\left(\mathrm{AM}^{-}\right)$from 45 days after inoculation to 90 days after inoculation. Data were periodically monitored (every four days) during greenhouse trial.

\begin{tabular}{|c|c|c|c|c|c|c|c|c|c|c|c|c|}
\hline \multirow[t]{2}{*}{ Treatments } & \multicolumn{12}{|c|}{$\begin{array}{c}\left.\text { Stomatal conductance (mmol } \mathrm{m}^{-2} \mathrm{~s}^{-1}\right) \\
\text { Days after inoculation }\end{array}$} \\
\hline & 46 & 50 & 54 & 58 & 62 & $66^{\circ}$ & 70 & 74 & 78 & 82 & 86 & 90 \\
\hline \multicolumn{13}{|l|}{ Mycorrhiza (M) } \\
\hline $\mathrm{AM}^{+}$ & $437^{\mathrm{a}}$ & $457^{\mathrm{a}}$ & $466^{\mathrm{a}}$ & $483^{\mathrm{a}}$ & $509^{a}$ & $522^{\mathrm{a}}$ & $541^{\mathrm{a}}$ & $522^{\mathrm{a}}$ & $499^{a}$ & $479^{a}$ & $462^{\mathrm{a}}$ & $411^{\mathrm{a}}$ \\
\hline $\mathrm{AM}^{-}$ & $386^{\mathrm{b}}$ & $406^{\mathrm{b}}$ & $430^{\mathrm{b}}$ & $449^{b}$ & $470^{\mathrm{b}}$ & $493^{b}$ & $513^{b}$ & $494^{b}$ & $476^{\mathrm{b}}$ & $445^{b}$ & $425^{b}$ & $391^{\mathrm{b}}$ \\
\hline Significance & $*$ & $*$ & $*$ & $*$ & $*$ & $*$ & $*$ & $*$ & $*$ & $*$ & $*$ & $*$ \\
\hline \multicolumn{13}{|c|}{ Hybrid cultivars (C) } \\
\hline Concerto F1 & $399^{b}$ & $417^{b}$ & $434^{b}$ & $446^{\mathrm{b}}$ & $477^{\mathrm{b}}$ & $493^{b}$ & $504^{b}$ & $487^{\mathrm{b}}$ & $465^{b}$ & $441^{\mathrm{b}}$ & $419^{b}$ & $394^{\mathrm{b}}$ \\
\hline Madrigal F1 & $415^{\mathrm{a}}$ & $437^{b}$ & $455^{\mathrm{a}}$ & $476^{\mathrm{a}}$ & $496^{\mathrm{a}}$ & $514^{\mathrm{a}}$ & $538^{a}$ & $519^{a}$ & $494^{\mathrm{a}}$ & $475^{\mathrm{a}}$ & $440^{\mathrm{a}}$ & $413^{a}$ \\
\hline Opal F1 & $421^{\mathrm{a}}$ & $439^{b}$ & $454^{\mathrm{a}}$ & $475^{\mathrm{a}}$ & $495^{\mathrm{a}}$ & $515^{\mathrm{a}}$ & $537^{a}$ & $517^{a}$ & $492^{\mathrm{a}}$ & $479^{a}$ & $442^{a}$ & $410^{\mathrm{a}}$ \\
\hline Significance & $*$ & $*$ & $*$ & $*$ & $*$ & $*$ & $*$ & $*$ & $*$ & $*$ & $*$ & $*$ \\
\hline \multicolumn{13}{|l|}{ Interaction } \\
\hline $\mathrm{MxC}$ & $\mathrm{S}$ & $\mathrm{S}$ & $\mathrm{S}$ & $\mathrm{S}$ & $\mathrm{S}$ & $\mathrm{S}$ & $\mathrm{S}$ & $\mathrm{S}$ & $\mathrm{S}$ & $\mathrm{S}$ & $\mathrm{S}$ & $\mathrm{S}$ \\
\hline
\end{tabular}

Means in each column followed by different letters are significantly different ( $\mathrm{P} \leq 0.05)$ according to Fisher's Least Significant Differences test; $\mathrm{S}$, significant; *not significant ( $\mathrm{P} \leq 0.05)$.

Table 3. SPAD values of three hybrid cultivars of artichokes (Madrigal F1, Opal F1, Concerto F1) inoculated with Glomus viscosum strain $\mathrm{A6}\left(\mathrm{AM}^{+}\right)$compared to uninoculated plants $\left(\mathrm{AM}^{-}\right)$from 45 days after inoculation to 90 days after inoculation. Data were periodically monitored (every four days) during greenhouse trial.

\begin{tabular}{|c|c|c|c|c|c|c|c|c|c|c|c|c|}
\hline \multirow[t]{2}{*}{ Treatments } & \multicolumn{12}{|c|}{$\begin{array}{c}\text { SPAD values } \\
\text { Days after inoculation }\end{array}$} \\
\hline & 46 & 50 & 54 & 58 & 62 & 66 & 70 & 74 & 78 & 82 & 86 & 90 \\
\hline \multicolumn{13}{|l|}{ Mycorrhiza (M) } \\
\hline $\mathrm{AM}^{+}$ & $34.3^{\mathrm{a}}$ & $34.8^{\mathrm{a}}$ & $37.5^{\mathrm{a}}$ & $38.6^{\mathrm{a}}$ & $39.6^{\mathrm{a}}$ & $40.9^{\mathrm{a}}$ & $41.8^{\mathrm{a}}$ & $42.6^{\mathrm{a}}$ & $43.9^{\mathrm{a}}$ & $45.4^{\mathrm{a}}$ & $46.5^{\mathrm{a}}$ & $47.4^{\mathrm{a}}$ \\
\hline $\mathrm{AM}^{-}$ & $31.9^{b}$ & $32.5^{b}$ & $34.7^{\mathrm{b}}$ & $36.5^{b}$ & $37.5^{\mathrm{b}}$ & $38.6^{\mathrm{b}}$ & $39.4^{\mathrm{b}}$ & $40.2^{\mathrm{b}}$ & $40.9^{b}$ & 41.7 & $43.5^{\mathrm{b}}$ & $44.7^{\mathrm{b}}$ \\
\hline Significance & $*$ & $*$ & $*$ & $*$ & $*$ & $*$ & $*$ & $*$ & $*$ & $*$ & $*$ & $*$ \\
\hline \multicolumn{13}{|c|}{ Hybrid cultivars (C) } \\
\hline Concerto F1 & $31.8^{b}$ & $32.5^{\mathrm{b}}$ & $34.1^{\mathrm{c}}$ & $36.4^{\mathrm{b}}$ & $37.2^{\mathrm{b}}$ & $38.1^{\mathrm{c}}$ & $38.6^{\mathrm{b}}$ & $38.9^{b}$ & $39.0^{c}$ & $39.7^{c}$ & $39.7^{c}$ & $40.7^{c}$ \\
\hline Madrigal F1 & $33.4^{\mathrm{a}}$ & $34.8^{\mathrm{a}}$ & $38.1^{\mathrm{a}}$ & $39.4^{\mathrm{a}}$ & $40.8^{\mathrm{a}}$ & $41.5^{\mathrm{a}}$ & $42.0^{\mathrm{a}}$ & $42.9^{\mathrm{a}}$ & $45.4^{\mathrm{a}}$ & $46.5^{\mathrm{a}}$ & $49.2^{\mathrm{a}}$ & $50.0^{\mathrm{a}}$ \\
\hline Opal F1 & $34.0^{\mathrm{a}}$ & $34.6^{\mathrm{a}}$ & $36.1^{\mathrm{b}}$ & $36.9^{b}$ & $37.7^{\mathrm{b}}$ & $39.8^{\mathrm{b}}$ & $41.2^{\mathrm{a}}$ & $42.5^{\mathrm{a}}$ & $42.8^{b}$ & $44.0^{\mathrm{b}}$ & $46.4^{\mathrm{b}}$ & $48.0^{\mathrm{b}}$ \\
\hline Significance & $*$ & $*$ & $*$ & $*$ & $*$ & $*$ & $*$ & $*$ & $*$ & $*$ & $*$ & $*$ \\
\hline \multicolumn{13}{|l|}{ Interaction } \\
\hline $\mathrm{MxC}$ & S & $\mathrm{S}$ & $\mathrm{S}$ & S & S & $\mathrm{S}$ & $\mathrm{S}$ & S & $\mathrm{S}$ & S & $\mathrm{S}$ & $\mathrm{S}$ \\
\hline
\end{tabular}

sented in Table 4 on the physiological status of plantlets clearly revealed that mycorrhizal treatments improved the relative water content of inoculated plantlets compared to controls. Significant differences in relative water content of leaves were observed among the artichoke hybrids. The two-way analysis of variance (Table 4) showed that hybrid Opal F1 gave the best result in terms of relative water content. Proline accumulation in leaf tissue (Figure 2) was improved in mycorrhizal treatments, especially for hybrid Opal F1.

\section{Discussion}

Considering the plant-fungus interaction, the extent of mycorrhizal colonization of the root system and related plant responses were expected to vary in different plant-fungus combinations (Smith and Read, 1997). The differences in the mycorrhizal colonization rate could be attributed to the differences in mycorrhizal dependency among the
Table 4. Leaf relative water content (LRWC) in three hybrid cultivars of artichokes (Madrigal F1, Opal F1, Concerto F1) inoculated with Glomus viscosum $\left(\mathrm{AM}^{+}\right)$compared to uninoculated plants $\left(\mathrm{AM}^{-}\right) 90$ days after mycorrhizal inoculation.

\section{Leaf relative water content (\%)}

\begin{tabular}{lc} 
Treatments (M) & \\
AM+ & $86.3^{\mathrm{a}}$ \\
AM- & $80.7^{\mathrm{b}}$ \\
Significance & $*$ \\
Hybrid Cultivars (C) & \\
Madrigal F1 & $83.2^{\mathrm{b}}$ \\
Opal F1 & $84.9^{\mathrm{a}}$ \\
Concerto F1 & $82.4^{\mathrm{b}}$ \\
Significance & $*$ \\
\hline M x C & $\mathrm{S}$ \\
\hline
\end{tabular}

S, significant; values with different letters are significantly different according to Fisher's Least Significant Differences test $(\mathrm{P} \leq 0.01)$. 
hybrid artichoke cultivars. Notably, Madrigal F1 and Opal F1 showed a greater affinity with Glomus viscosum. Concerto F1 had lower mycorrhizal dependency and colonization that led to lower symbiosis influences on altering the physiology of mycorrhizal plants.

For each artichoke hybrid cultivar, all morphological parameters studied were significantly increased by mycorrhizal symbiosis in agreement with previous research (Ruta et al., 2003; Morone Fortunato et al., 2005). Greater root density would form higher surface absorption areas of roots mainly due to external hyphal growth in the soil (Hardie and Leyton, 1981). External hyphae took part directly in water uptake and transport (Wu and Xia, 2004). The increased leaf relative water content in mycorrhizal artichokes might be due to an improvement in the water uptake by the mycorrhizal root system through an extra-radical phase (Ruiz-Lozano et al., 1995; Vazquez et al., 2001, Wu and Xia, 2006).

During the period of the experiment, mycorrhizal plants presented higher values of stomatal conductance that would be consistent with the higher rates of gas exchange. This physiological adaptation could be necessary to supply the carbon needs of fungal symbionts (Augé $e t$ al., 2008). The best water content of mycorrhizal plants supported the metabolism of the leaf mesophyll. In fact, tissue chlorophyll content was enhanced by mycorrhiza. Mycorrhizal symbiosis resulted in a proline increase in leaf tissues. The increased proline content is a physiological strategy that provides the leaf with an osmotic mechanism for preventing excessive water loss and can also protect the cell metabolism by containing the protein denaturalization and/or by controlling

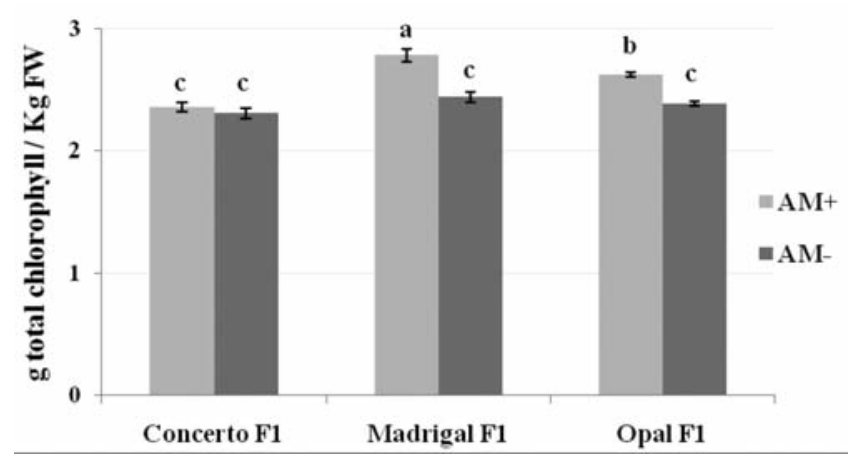

Figure 1. Chlorophyll content in three hybrid cultivars of artichokes (Madrigal F1, Opal F1, Concerto F1) inoculated with Glomus viscosum $\left(\mathrm{AM}^{+}\right)$compared to uninoculated plants (AM) 90 days after mycorrhizal inoculation. Values with different letters are significantly different according to Fisher's Least Significant Differences $(P \leq 0.01)$.

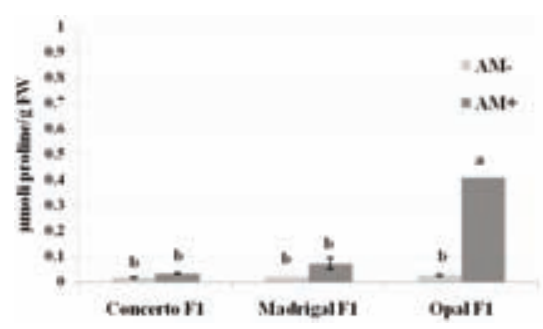

Figure 2. Proline content in fresh vegetal tissue in three hybrid cultivars of artichokes (Madrigal F1, Opal F1, Concerto F1) inoculated with Glomus viscosum strain $\mathrm{A6}(\mathrm{AM}+)$ compared to uninoculated plants (M-) 90 days after mycorrhizal inoculation. Values with different letters are significantly different according to Fisher's Least Significant Differences $(\mathbf{P} \leq \mathbf{0 . 0 1})$. the cell pH (Aspinall, 1981).

The proline accumulation, related to the biometric and physiological results obtained during the trial, could be interpreted as the physiological response of plant-fungus interaction that activates an endogenous production of proline, as reported by many authors (Ruiz-Lozano et al., 1995; Hatimi, 1999; Krishna et al., 2005). The enhanced chlorophyll level, the increased values of SPAD and of stomatal conductance, the major leaf relative water content might be responsible for increased photosynthesis in mycorrhizal artichokes that may be able to assimilate more $\mathrm{CO}_{2}$ and thereby to accumulate more biomass (Krishna et al., 2005; Estrada-Luna and Davies, 2003). The effectiveness of the symbiotic performance was particularly evident for hybrid cultivars Madrigal Fland Opal F1. The results obtained show that an effective mycorrhizal symbiosis between AM fungi and artichoke plantlets is possible.

In recent years, artichoke cultivation has met several economic difficulties which have reflected the agronomic and pathological problems of this crop. These have limited, sometimes severely, its production and the quality of the head making its cultivation uncompetitive.

This study underlines the importance of propagation of artichokes by seeds as a new technique as opposed to the traditional system. The benefits of artichoke propagation from seeds are: easy transplant, crop programmability, and high productivity.

The use of mycorrhizal inoculation in the early stages of nursery cultivation enhances the vigor and health of plants. Mycorrhizal inoculation has been proven to be an important tool in a more sustainable horticultural production of artichokes in the nursery, and represents a valid instrument to overcome the phytosanitary problems related to artichoke cultivation.

The practice of mycorrhizal inoculum is effective in improving the intrinsic quality of the artichoke plantlets produced in nurseries.

\section{References}

Al-Karaki G.N., 2006. Nursery inoculation of tomato with arbuscular mycorrhizal fungi and subsequent performance under irrigation with saline water. Sci. Hort. 109:1-7

Aspinall D., Paleg L.G., 1981. Proline accumulation. Physiological aspect. pp 205-240 in: Physiology and Biochemistry of Drought resistance in Plants. Academic Press, New York, NY, USA.

Augé R.M., Toler H.D., Sams C.E., Nasim G., 2008. Hydraulic conductance and water potential gradients in squash leaves showing mycorrhiza-induced increases in stomatal conductances. Mycorrhiza 18:115-121.

Azcón-Aguilar C., Barea J.M., 1997. Applying mycorrhiza biotechnology to horticulture: significance and potentials. Sci. Hort. 68:1-24.

Barea J.M., Azcòn R., Aguilar C., 2000. Micorrizazione e tecniche microbiologiche per migliorare l'attività radicale delle piante in vivaio. Frutticoltura 2:71-75.

Bates L.S., Waldren R.P., Teare I.D., 1973. Rapid determination of free proline for water stress studies. Plant Soil 39:205-207.

Bethlenfalvay G.J., Andrade G., Azcón-Aguilar C, 1997. Plant and soil responses to mycorrhizal fungi and rhizobacteria in nodulated or nitrate fertilized peas. Biol. Fert. Soils 24:164-168.

Cantrell I.C., Linderman R.G., 2001. Preinoculation of lettuce and onion with VA mycorrhizal fungi reduces deleterious effects of soil salinity. Plant Soil 233:269-281.

Ceccarelli N., Curadi M., Martelloni L., Sbrana C., Picciarelli P., Giovannetti M., 2010. Mycorrhizal colonization impacts on phenolic content and antioxidant properties of artichoke leaves and flower heads two years after field transplant. Plant Soil 335:311323.

Colla G., Rouphael Y., Cardarelli M.T., Tullio M., Rivera C.M., Rea E., 
2008. Alleviation of salt stress by arbuscular mycorrhizal in zucchini plants grown at low and high phosphorus concentration. Biol. Fert. Soils 44:501-509.

Copetta A., Lingua G., Bardi L., Masoero G., Berta G., 2007. Influence of arbuscular mycorrhizal fungi on growth and essential oil composition in Ocimum basilicum var. Genovese. Caryologia 60:106-110.

Cruz C., Green J.J., Watson C.A., Wilson F., Martins-Loução M.A., 2004. Functional aspects of root architecture and mycorrhizal inoculation with respect to nutrient uptake capacity. Mycorrhiza 14:177-184.

Estrada-Luna A.A., Davies F.T. Jr., 2003. Arbuscular mycorrhizal fungi influence water relations, gas exchange, abscisic acid and growth of micropropagated chile ancho pepper (Capsicum annuum) plantlets during acclimatization and post-acclimatization. J. Plant Physiol. 160:1073-1083.

Gendermann J.W., 1975. Vesicular-arbuscular mycorrhizae. In: J.G.Torrey and D.T. Clarcson (eds.) The development and Function of Roots. Academic Press, London, UK, pp 575-591.

Gianquinto G., Magnifico V., 2003. Aspetti tecnici innovativi nel vivaismo orticolo. Italus Hortus 10:26-35.

Green J.J., Baddeley J.A., Cortina J., Watson C.A., 2005. Root development in the Mediterranean shrub Pistacia lentiscus as affected by nursery treatments. J. Arid Environ. 61:1-12.

Gupta M.L., Prasad A., Ram M., Kumar S., 2002. Effects of the vesicular arbuscular mycorrhizal (VAM) fungus Glomus fasciculatum on the essential oil yield related cultivars of menthol mint (Mentha arvensis) under field conditions. Bioresource Technol. 81:77-79.

Hamel C., Dalpe Y., Furlan V., 1997. Indigenous populations of arbuscular mycorrhizal fungi and soil aggregate stability are major determinants of leek (Allium porrum L.) response to inoculation with Glomus intraradices Schenck \& Smith or Glomus versiforme (Karsten) Berch. Mycorrhiza 7:187-196.

Hajiboland R., Aliasgharzadeh A., Laiegh S.F., Poschenrieder C., 2010. Colonization with arbuscular mycorrhizal fungi improves salinity tolerance of tomato (Solanum lycopersicum L.) plants. Plant Soil 331:313-327.

Hardie K., Leyton L., 1981. The influence of vesicular-arbuscula mycorrhiza on growth and water relations of red clover. I. In phosphate deficient soil. New Phytol. 89:599-608.

Hatimi A., 1999. Effect of salinity on the association between root symbionts and Acacia cyanophylla Lind.: growth and nutrition. Plant Soil 216:93-101.

Hartmann H.T., Kester D.E., Davies F.T., Geneve R.L., 2002. Plant propagation Principles and Practises. Rev 7th ed. Prentice Hall by Pearson Education, Inc., Upper Saddle River, NJ, USA.

Jeffries P., Gianinazzi S., Perotto S., Turnau K., Barea J.M., 2003. The contribution of arbuscular mycorrhizal fungi in sustainable maintenance of plant health and soil fertility. Biol. Fert. Soils 37:1-16.

Kapoor R., Giri B., Krishna G.M., 2004. Improved growth and essential oil yield and quality in Foeniculum vulgare Mill. on mycorrhizal inoculation supplemented with P-fertilizer. Bioresource Technol. 93:307-311.

Krishna H., Singh S.K., Sharma R.R., Khawale R.N., Grover M., Patel V.B., 2005. Biochemical changes in micropropagated grape (Vitis vinifera L.) plantlets due to arbuscular-mycorrhizal fungi (AMF) inoculation during ex vitro acclimatization. Sci. Hort. 106:554-567.

Lynch J., 1995. Root architecture and plant productivity. Plant Physiol. 109:7-13.

Matsubara Y., Hadara T., 1996. Effect of arbuscular mycorrhizal fungus infection on growth and mineral nutrient content of Asparagus officinalis L. seedlings. J. Jap. Soc. Hortic. Sci. 65:303-309.

Morone-Fortunato I., Ruta C., Castrignanò A., Saccardo F., 2005. The effect of mycorrhizal symbiosis on the development of micropropagated artichokes. Sci. Hort. 106:472-483.

Pelaez C., Olivares E., Cuenca G., Izaguirre-Mayoral M.L., 2010. Manganese modulates the responses of nitrogen-supplied and Rhizobium-nodulated Phaseolus vulgaris L. to inoculation with arbuscular mycorrhizal fungi. Soil Biol. Biochem. 42:1924-1933.

Phillips J.M., Hayman D.S., 1970. Improved procedures for clearing roots and staining parasitic and vesicular-arbuscular mycorrhizal fungi for rapid assessment of infection. Trans. Br. Mycol. Soc. $55: 158-161$.

Rabie G.G., Almandini A.M., 2005. Role of bioinoculants in development of salt-tolerance of Vicia faba plants under salinity stress. Afr. J. Biotechnol. 4:210-223.

Ruiz-Lozano J.M., Azcon R., Gomez M., 1995. Effect of arbuscular-mycorrhizal Glomus species on drought tolerance: physiological and nutritional plant responses. Appl. Environ. Microbiol. 61:456-460.

Ruta C., Morone-Fortunato I., Tagarelli A., 2003. Production of micropropagated melon plantlets adapted to saline environment. Acta Hortic. 609:257-262.

Sensoy S., Demir S., Turkmen 0., Erdic C., Sayur 0.B., 2007. Responses of some different pepper (Capsicum annum L.) genotypes to inoculation with two different arbuscular mycorrhizal fungi. Sci. Hort. 113:92-95.

Smith S.E., Read D.J., 1997. Mycorrhizal symbiosis. 2nd ed. Academic Press, San Diego, CA, USA.

Strain H.H., Svec W.A., 1966. Extraction, separation, estimation and isolation of chlorophylls. In: L.P. Vernon and G.R. Seely (eds.) The Chlorophylls. Academic Press, New York, NY, USA, pp 21-66.

Taylor J., Harrier L.A., 2001. A comparison of development and mineral nutrition of micropropagated Fragaria $\times$ ananassa cv. Elvira (strawberry) when colonised by nine species of arbuscular mycorrhizal fungi. Appl. Soil Ecol. 18:205-215.

Tennant D., 1975. A test of a modified line intersect method of estimating root length. J. Ecol. 63:995-1001.

Trouvelot A., Kouch J., Gianinazzi-Pearson V., 1986. Mesure du taux de mycorhization VA d'un système radiculaire: Recherche of method d'estimation ayant une signification fonctionelle. Les Mycorhizes: Phisiologie and Genetique. pp 217-221 in 1st Seminaire Dijon, INRA Ed., Paris, France.

Vàzquez M.M., Azcòn R., Barea J.M., 2001. Compatibility of a wild type and its genetically modified Sinorhizobium strain with two mycorrhizal fungi on Medicago species as affected by drought stress. Plant Sci. 161:347-358.

Westphal A., Snyder N.L., Xing L.J., Camberato J.J., 2008. Effects of inoculations with mycorrhizal fungi of soilless potting mixes during transplant production on watermelon growth and early fruit yield. Hort Science 43:354-360.

Wu Q., Xia R.X., 2004. The relation between vesicular-arbuscular mycorhizae and water metabolism in plants. Chin. Agr. Sci. Bull. 20:188-192.

Wu Q., Xia R.X., 2006. Effects of arbuscular mycorrhizal fungi on leaf solutes and root absorption areas of trifoliate orange seedlings under water stress conditions. Front. For. China 3:312-317.

Yamasaki S., Dillenburg L.R., 1999. Measurements of relative water content in Auracaria angustifolia. Rev. Bras. Fisiol. Veg. 11:69-75. 